\title{
Recurrent cesarean scar pregnancy treated successfully with uterine artery chemoembolization
}

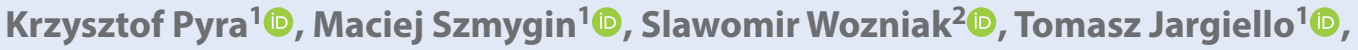 \\ Tomasz Paszkowski² \\ ${ }^{1}$ Department of Interventional Radiology and Neuroradiology, Medical University of Lublin, Poland \\ ${ }^{2}$ Department of Gynecology, Medical University of Lublin, Poland
}

Key words: cesarean scar pregnancy; recurrent; chemoembolization

Cesarean scar pregnancy (CSP) is a rare but life-threatening condition representing approximately six percent of all ectopic pregnancies in women with history of cesarean delivery [1]. Treatment options vary from medical management, surgical procedures and endovascular approach and aim to prevent serious complications (massive hemorrhage, uterine rupture) and preserve fertility [2]. Superiority of any from the above-mentioned treatment modalities as well as their impact on subsequent pregnancies is a matter of an on-going debate. To date, only few reports on recurrent cesarean scar pregnancy (RCSP) are available in the literature $[3,4]$. We hereby present such a case treated successfully with uterine artery chemoembolization (UAC).

A 34-year old female G6P3114 (3 cesarean deliveries, 1 miscarriage, 1 ectopic pregnancy - CSP treated with UAC and 4 living children) was admitted to the Department of Gynecology for prenatal care at eight weeks of gestation. The patient reported minor vaginal bleeding a few days prior to the examination. A physical examination disclosed no abnormalities. Laboratory tests revealed a serum $\beta$-hCG of $49.796 \mathrm{mIU} / \mathrm{mL}$. The hemoglobin and red blood cell counts were within the reference ranges. Transvaginal ultrasound (TVUS) showed a gestational sac measuring $50 \times 25 \mathrm{~mm}$ located in the cesarean scar (Fig. 1A, B). CRL of $0.44 \mathrm{~cm}$ corresponded to gestational age of six weeks and two days. Fetal heart rate was detected.

After multidisciplinary consultation and informed consent from the patient she was referred for UAC. The reason for this treatment was twofold. Firstly, the dose of methotrexate is lower compared to systemic therapy. Secondly, temporary embolization of uterine arteries reduces the blood loss during suction curettage. In all sterile conditions selective catheterization of both uterine arteries was performed (Fig. 1C, D). A total dose of $50 \mathrm{mg}$ methotrexate, half of which was mixed with gelatin sponge powder, was administered bilaterally until complete obliteration of the vascular supply to the gestational sac. In control TVUS examination 24-hours after the procedure no evidence of fetal cardiac activity was noted, and suction curettage was performed. Gradual drop of serum $\beta$-hCG levels was observed in the following days. After five days the patient was discharged in good clinical condition with strict precaution to return to the emergency in case of any disturbing symptoms.

The significant increase in cesarean deliveries observed in the last half of century has led to the increase in the rate of CSP. However, cases of RCSP are extremely rare and since first reported by Hasegawa et al. [4], only a limited number of patients is available in the literature. Currently there are no guidelines for the management of neither CSP nor RCSP, but early termination is recommended. Treatment possibilities include non-surgical (intragestational/systemic MTX administration) and surgical (laparoscopic evacuation, open excision, embolization) methods. Although some authors suggest that the management of CSP might correlate with the occurrence of RCSP the evidence is scarce [5]. Therefore, all patients with history of CSP require special attention and should undergo early sonography in subsequent pregnancies in order to ensure a normal position of the pregnancy in the uterus and exclude RCSP.

Corresponding author:

Maciej Szmygin

Department of Interventional Radiology and Neuroradiology, Medical University of Lublin, Aleje Racławickie 1, 20-059 Lublin, Poland

e-mail: mszmygin@gmail.com

This article is available in open access under Creative Common Attribution-Non-Commercial-No Derivatives 4.0 International (CC BY-NC-ND 4.0) license, allowing to download articles and share them with others as long as they credit the authors and the publisher, but without permission to change them in any way or use them commercially. 


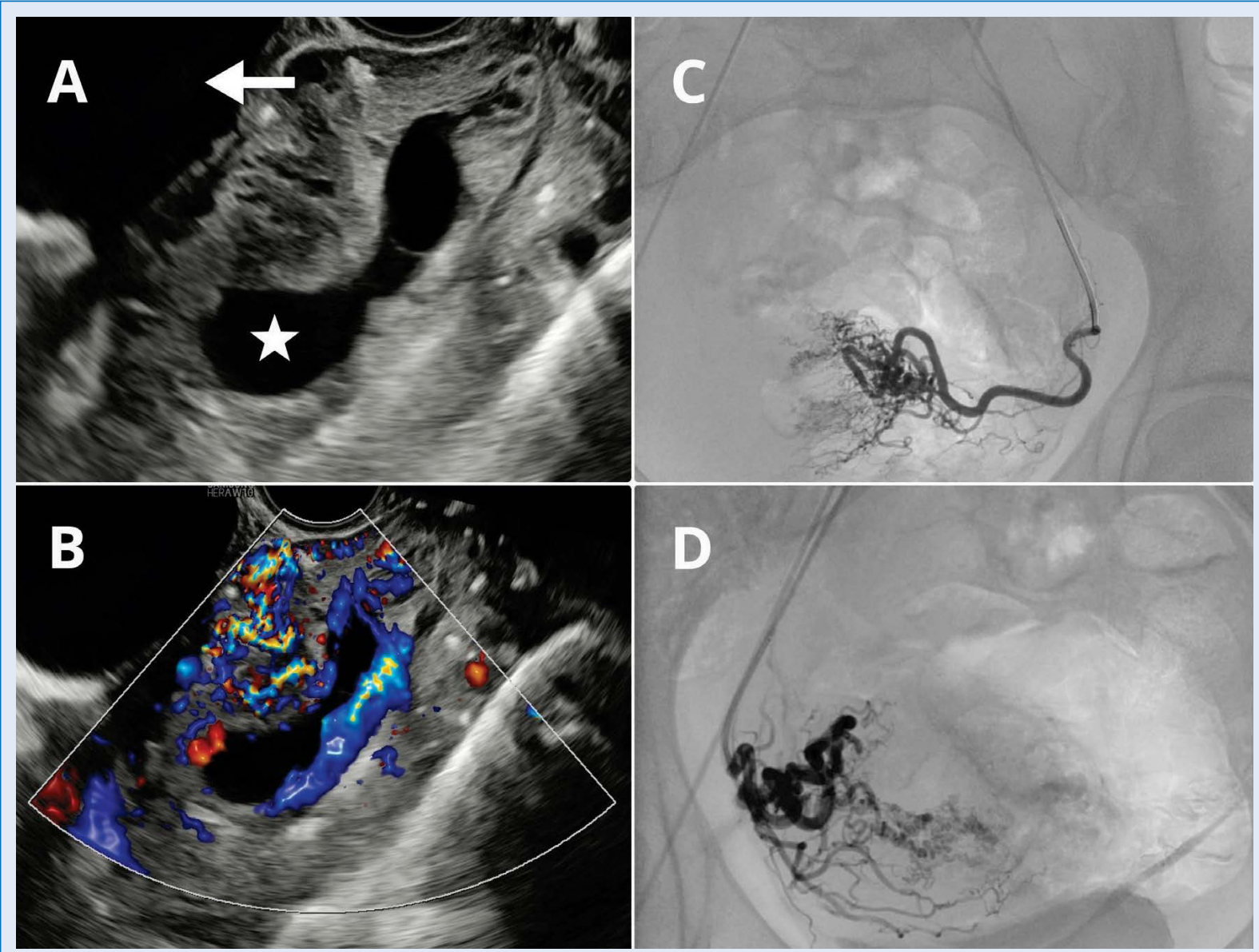

Figure 1. Transvaginal ultrasound examination showing; A. Gestational sac (star) with its lower part in the prior cesarean scar and urinary bladder (arrow); B. Numerous blood vessels. C, D. DSA (Digital Subtraction Angiography) showing selective angiography of uterine arteries

\section{Conflict of interest}

None.

\section{REFERENCES}

1. Seow KM, Huang LW, Lin YH, et al. Cesarean scar pregnancy: issues in management. Ultrasound Obstet Gynecol. 2004; 23(3): 247-253, doi: 10.1002/uog.974, indexed in Pubmed: 15027012.

2. Gonzalez N, Tulandi T. Cesarean Scar Pregnancy: A Systematic Review. J Minim Invasive Gynecol. 2017; 24(5): 731-738, doi: 10.1016/j.jmig.2017.02.020, indexed in Pubmed: 28268103.

3. Gupta S, Pineda G, Rubin S, et al. Four consecutive recurrent cesarean scar pregnancies in a single patient. J Ultrasound Med. 2013; 32(10): 1878-1880, doi: 10.7863/ultra.32.10.1878, indexed in Pubmed: 24065271.

4. Hasegawa J, Ichizuka K, Matsuoka R, et al. Limitations of conservative treatment for repeat Cesarean scar pregnancy. Ultrasound Obstet Gynecol. 2005; 25(3): 310-311, doi: 10.1002/uog.1843, indexed in Pubmed: 15736210.

5. Ben Nagi J, Ofili-Yebovi D, Sawyer E, et al. Successful treatment of a recurrent Cesarean scar ectopic pregnancy by surgical repair of the uterine defect. Ultrasound Obstet Gynecol. 2006; 28(6): 855-856, doi: 10.1002/uog.3843, indexed in Pubmed: 17031873. 